\title{
Historical Stages and the Modern Models of Children and Adults Territorial Communities
}

\author{
Mikhail Naumovich Pevzner ${ }^{1}$, Roza Moiseievna Sheraizina ${ }^{1}$, Petr Anatolievich Petriakov ${ }^{1}$, Irina Alexandrovna \\ Donina $^{1}$, Elena Vasilievna Migunova ${ }^{1} \&$ Alexander Glebovich Shirin ${ }^{1}$ \\ ${ }^{1}$ Yaroslav-the-Wise Novgorod State University (NovSU), Veliky Novgorod, Russia \\ Correspondence: Petr Anatolievich Petriakov, ul. B. St. Petersburgskaya, 41, Veliky Novgorod, 173003, Russia.
}

\author{
Received: March 11, 2015 Accepted: March 30, 2015 Online Published: May 22, 2015 \\ doi:10.5539/res.v7n9p97 \\ URL: http://dx.doi.org/10.5539/res.v7n9p97
}

The study is funded by the Ministry of Education and Science of the Russian Federation within the framework of the project of the state order $\# 27.1559 .2014 / K$ for the execution of research work.

\begin{abstract}
The article reveals the ongoing research, the object of which is intergenerational relations in children and adults territorial communities. Based on historical and pedagogical analysis of research of the problem and understanding of global challenges to the modern education, the authors provide scientific substantiation of the development process of intergenerational relations in children and adults communities. A conceptual model of knowledge about children and adults educational territorial communities is worked out; the most important historical stages in the development of children and adults territorial communities are highlighted; major theoretical, historical and pedagogical background of the theories regarding children and adults communities are identified; a comparative analysis of the diversity of models for children and adults territorial communities in Russia and abroad is implemented; the basic models of modern children and adults territorial communities are identified and theoretically proved, taking into account the different interpretations of the term of "territory". The results significantly extend the research methodology for the problems of children and adults communities represented in the Russian and foreign studies. The results of the study are partially implemented and will continue to be implemented into the practice of formation and development of children and adults communities as educational institutions, and in certain regions, depending on the characteristics of the community models. The results can be used during lectures and seminars on the overall social and comparative pedagogy, social psychology at the universities, as well as in the training of school principals, coordinating councils of the territories, and organizers of curricular and extra-curricular work with children and adolescents.
\end{abstract}

Keywords: history, historical and pedagogical research, education, social and comparative pedagogy, children and adults community, children and adults territorial community, intergenerational relations, joint activities, partnership activities, intergenerational productive interaction

\section{Introduction}

\subsection{Introduce the Problem}

The changes taking place in the modern human being, reflected in the restructuring of human mentality, changing goals, values, attitudes and the onset of new needs and new opportunities require a special study of the behaviour of the modern human being in uneven heterogeneous groups to determine their effectiveness and opportunities for interconnection, interoperability and understanding of people of different generations, as well as their human potential. In this context, the strategy of the research is defined. It is the scientific substantiation of trends and opportunities of formation and development of children and adults territorial communities. If the problem is solved, it will actualize the problem of intergenerational interaction, reveal divergent patterns of interaction of children and adults in Russia and abroad, identify their strengths and weaknesses; develop a program of empirical research methods and needs of the regions in the organization of children and adults communities; create a structural-functional diagram of the modern children and adults territorial communities; develop a concept design alternative models of formation for children and adults communities with the features and capabilities of the territory; investigate the mechanisms of implementation of alternative models in practice, 
develop recommendations for their use in territorial educational systems.

\subsection{Explore Importance of the Problem}

The relevance of scientific research is due to the need of scientific research addressing the following issues.

The first group of problems is related to intergenerational relations, with contradictory trends and convergence gap of generations, with the changes that are taking place in the socio-psychological characteristics of different age groups. Today the problem of "fathers and children" takes a new shape. In many ways, they are associated with prefigurative culture where the younger generation more rapidly acquires social experience and transfers it to not only their contemporaries, but also to the older generation. The tendency to education is enhancing during all the life.

The second group of problems includes certain distortions that have occurred in the pedagogics and educational strategies of the post-perestroika period. This strategy is mainly focused on the individualization of education and the educational process, stressing the importance of individual and differentiated approach to pedagogy and ignoring the principles of community and collective education, which were declared as the remnants of the past. Under these conditions, such phenomena as individualism, social apathy, isolation, social laziness, ignoring the interests of other individuals and groups spread. The problem for neutralizing such negative phenomena and building productive interaction between members of different generations, between children and adults, has ceased to be a problem of single family, individual schools and began to acquire the character of social need in the formation of the territory in formation of a children and adults community.

\subsection{Describe Relevant Scholarship}

The content of this article reflects the results of the study to address the above-mentioned problems, and significantly expands the existing fund of knowledge in teaching children about the community, which is represented in the theories of children community and community pedagogy (Makarenko, 2003; Suhomlinskiy, 2001; Shatskiy, 2011); reformist pedagogics (Wentzel, 1993; Montessori, 1993; Neill, 2000); humanistic psychology (Asmolov, 1990; Zinchenko, 1994; Leontiev, 2001; Maslow, 2002); theory of social and educational communities (Davydov, 2008; Slobodchikov, 2000; Shustova, 2009).

One of the last papers among devoted to this problem is the scientific publication named "Children community as a socio-pedagogical phenomenon" (Shustova et al., 2014). This publication contains the phenomenology of children communities, at that the authors, using different research methods (observation, monographic study, generalization of expert evaluations, compilation of best teaching experience), provided a description of communities, which include modern schoolchildren and students. The authors reveal the role of an adult in the formation and development of the modern society. This publication was a continuation of research by I. Yu. Shustova named "Factor of a children and adults community in the education and development of youth subjectivity" (Shustova, 2009). What problems were solved by the authors of the papers listed above in this field of study? According to the authors, this includes, firstly, the following: systematization of theoretical and methodological approaches to understanding a children's community as a socio-pedagogical phenomenon; development of children's prosocial typology of communities; determine the conditions of actualization of educational potential for a children's community; identification of the place and role of an adult in the formation and development of a children's community; definition of opportunities for a children's community to influence the social environment.

\subsection{State Hypotheses and Their Correspondence to Research Design}

Understanding the studied processes reveals a number of new problematic issues that were not previously covered in the scientific literature. These issues include the following: what is the composition, the nature of relationships and connections, values, mode of operation and development of a children and adults territorial community? What are the basic models of children and adults territorial communities? To what extent does the choice of model depend on the type of the territory in which the community is formed? Is it possible for a children and adults territorial educational community to be a single construct, which is a value-semantic space, or a set of individual social cells, united by shared interests associated with the interests of the territory, located in the complex and close cooperation with each other, under the patronage, mediation, collaboration and co-management by the territorial government?

Finding answers to these questions and more makes the study relevant and in demand for both the pedagogical science and territorial communities in different countries. Therefore, the main objective of the study was to develop a conceptual framework of intergenerational relations in children and adults territorial communities. This conceptual scheme is the theoretical basis of trends and potential development of intergenerational relations 
in children and adults territorial communities. In addition to this objective, the study suggested the following: identification of the most important historical stages in the development of scientific knowledge about the process of formation and development of children and adults communities; definition of the leading theoretical, historical and educational prerequisites for the development of the theory of children and adults communities; identifying and theoretical justification or the leading models of modern children and adults territorial communities, taking into account the different interpretations of the term of "territory".

\section{The Methodology of the Research}

\subsection{The Methodological Basis of the Research}

Methodology in the context of our study is considered as the doctrine of the organization of the activity, and the activity means an active human interaction with the surrounding reality, in which the person acts as the subject of deliberate action on the object, thus satisfying their needs (Zinchenko \& Morgunov, 1994) .

Methodology summarizes the rational forms of organization activities conducted in broad socio-historical practice. In modern conditions in connection with the accelerated social development, including industrial relations, a new form of organization activity is upcoming - the organizational culture and its characteristic style - design and technological culture, an important characteristic of which is the technology community based on the principle of communication and professional relationship (Nikitin, 1998).

The methodological basis of the research is consistent methodological platform, including the following: the integrated approach to the development of intergenerational relations (focused on a comprehensive study of children and adults communities in view of its key features, value orientations, their living conditions, the nature of social relations, relationships, interactions and modes of communication); the comparative approach (allows studying the process of formation and development of children and adults communities compared to the intergenerational projects and practices in Russia and abroad); the sociological approach (considering the nature, content and direction of relations between people belonging to the community); and the spatial approach (determining factors of stability limited area, on which the social interaction between children and adults is carried out: the psychological approach (considering a children and adults community as an instrument of cohesion, integration, solidarity and understanding of people, as well as exploring their feelings and experiences related to the intergenerational interaction).

The study used the conceptual definition ("the development of intergenerational relations", "children and adults territorial communities", "design and technological culture for community organizations") and operational definitions ("synergy", "partnership activities", "children and parents community", "professional community", and "virtual community").

\subsection{Participant (Subject) Characteristics}

Taking into account the above-mentioned views on the methodology and purpose of the study of intergenerational relations, there was formed a group looking for ways to solve the above-mentioned problems, taking into account the interests and the results of its research activities, practical experience and professional interests (designing territorial system of formal, informal and non-formal education for children and adults; organization of children and adults creative communities; territorial modelling of virtual communities of educational process, implementation of the ideas of reformist pedagogy and corporate pedagogy).

The experimental study of the territorial needs of the education system to address the development of interdisciplinary relations in children and adults communities involved 210 school-age children, 160 parents, 70 high school students and undergraduates, and 32 teachers.

The study was conducted in vivo of educational institutions activity.

Selection of the experimental sites was due to the activity of educational institutions in project activities at the municipal level, regional, and the Federation. The leaders of these institutions in recent years were named as the winners of the All-Russian competitions.

\subsection{Sampling Procedures}

The procedure for selecting respondents included the two approaches to the selection of respondents: the first was based on the selection criteria (82.9\%) and the second - considered the personal initiative and desire to participate in the experiment (17.1\%). Relations with the participants to the experiment were based on agreements on cooperation between the educational institutions and the university. 


\subsubsection{Sample Size, Power, and Precision}

The experimental study of the needs of the territorial educational system in children and adults communities was conducted in stages: statement of the purpose of the study (to identify the needs of the territorial system in children and adults communities in which there is a possibility of intergenerational relations); definition of a system of indicators (significance of intergenerational relations in terms of creation and functioning of children and adults communities, the importance of establishing certain conditions for the establishment of effective children and adults communities, the choice of strategy for the formation of a children and adults community in a certain area and to identify the problems of forming a successful children and adults community with different groups of children); development of working tools; analysis of the collected information (the methods and procedures for obtaining information (surveys, statistics, internal information, independent sources-reports, compilations, etc.), data processing, analysis and research of the received test materials, the definition of the stages and timing of the study.

In order to improve the quality of measurements in the course of the experiment, the various forms of assessors' training were used (heads and educators of educational institutions, teachers of high schools). Thus, for example, the professional development programs "Effective contract", "Educational management in heterogeneous groups and organizations", "Secrets of children's behaviour", "Tutoring babies" and others were tested.

\subsubsection{Measures and Covariates}

The pursuance of theoretical and experimental study of intergenerational relations in children and adults territorial communities used methods of system-structural analysis allowed revealing the relationships and dependencies that exist within communities and providing separate models for children and adults territorial communities; methods of historical-reflective analysis, which helped to explore the various stages in the development of children and adults communities; comparative methods, which provided a comparative analysis of the diversity of models for children and adults territorial communities in Russia and abroad, nomothetic (generalizing) methods allowed creating a holistic view of the object of the study, as well as questionnaires methods of interviewing, conversation, creating focus groups, and statistical processing of the empirical data.

During the experimental study, in the subsequent phases, it is planned to use the following methods having complex features: "V. Fey's scale" for the diagnostics of acceptance of others with the appropriate type of response in the communication process; "D. Campbell scale"- the diagnostic of goodwill, i. e. mental status, feature of a human being, expressed in empathy in relation to the people around; the method by $\mathrm{K}$. $\mathrm{N}$. Thomas for identification of typical ways for a human being of responding to conflict situations, identification of trends of their relations in difficult conditions; "Tolerant behaviour diagnostics. Incomplete sentences" by U. A. Kuhareva.

\subsubsection{Research Design}

The experiment was performed in vivo. Experimental investigation was carried out as an intrasubjective (children, teachers, heads) and intersubjective (children, teachers, parents, social partners, executives) one.

\section{Research Results}

This section provides a conceptual and scientific justification for the phased development of scientific knowledge about the process of becoming for children and adults territorial community based on the selected criteria of periodization. In addition, the presented materials include the empirical study of the basic characteristics of children and adults educational communities (on the example of the Novgorod region).

\subsection{The Main Historical Stages of the Development of Scientific Knowledge about the Process of Formation and Development of Children and Adults Communities}

The comparative analysis of the formation and development of a children and adults community in Russia and abroad was based on the study of Russian, English and German-language scientific literature relating to this issue. The basis for allocation of the development stages of knowledge about children and adults communities is in the following criteria: the nature of intergenerational relations in children and adults communities, primarily in the family and at school; the predominant style of education; subject position of the child and the adult in a children and adults community; the impact of society on the formation of children and adults communities.

In accordance with these criteria, the following stages have been identified:

- Early historical stage which synthesized and accumulated the centuries-old experience of intergenerational relations in the family and society (from ancient times until the middle of the XIX century); 
- Reformist stage, characterized by the spread in Russia and Western Europe of ideas of reform pedagogy and free education that caused the direction of children and adults communities, first of all, to the family and school and to the child; increase of pedagogical and centrist trends in education and training (end of the XIX - beginning of XX century);

- Development stage of pedagogy of the community and a group of children associated with the increasing influence of social factors on the development of children and adults communities and spread of the doctrine of education in the community and through the community (XX century);

- Pluralistic stage associated with the development of a variety of different models of children and adults communities (end of the XX - the beginning of the XXI century).

\subsubsection{Characteristics of the Early Historical Period}

Analysis of the people's pedagogical heritage in the context of the problem shows that the pagan times in ancient Rus were marked with the formation of experience of intergenerational relations in the family and society that found its concrete expression: in imbued with love, respect and trust relationships of the child with the mother; in the development and use of educational resources, taking into account the age characteristics and interests of children and focused on communication and interaction with the mother, grandmother and other relatives; in involvement of older children into the world of ancient art, religious practices, household and labour traditions of their nationality; raising a sense of community in the child as a characteristic of the Russian people, in which people can comprehend and realize itself only in fraternal communion with others.

The study revealed that among the extant written sources, the most complete and accurate description of the system of intergenerational relations is presented in one of the most remarkable monuments of ancient literature - the "Domostroy". The "Domostroy" is a collection of instructions about building relationships, life, management, and education of children in the Russian patriarchal family (Sylvester, 1994). The comparative analysis revealed earlier foreign counterparts of the "Domostroy": "Summa on housecraft" by Ibn Sina "The advices of the father to the son" by Smil Flaska, "Discourse on the management of the family" by Pandolfini, the Czech "Christian Doctrine" et al., which indicates the presence of literary and general cultural influence by other nations on Russia. The "Domostroy" is distinguished from foreign works by the author's reliance on centuries-old cultural traditions of the Russian people and the use of specific sources, among which are the "Instruction from Vladimir Monomah", domestic didactic collections called "Izmagrad", "Gilded chain" and others, and monastic charters.

Comparative analysis of intergenerational relations in Russia and Germany demonstrated that in the Middle Ages due to financial convenience and the need to earn their living on their own, it was preferable to live in large families, numbering at least three generations. The older generation was engaged in education of juniors, the secondary generation, the most workable, performed basic work in the home, on the field, in the vegetable and fruit gardens. Regarding to non-family communities, then up to the twentieth century, they were most often composed of individuals of the same sex and about the same age. If speaking about the economic reasons, then a family or a community consisting of several generations was forced to live together, then, as indicated by German scientists, it often led to conflicts than to peaceful coexistence. In addition, it should be noted that the life expectancy was much smaller and the older generation often did not see their grandchildren because they died before birth or while they were babies (Keil, 2012, p. 15).

Authoritarian tradition of education and development of intergenerational relations in this way were observed in the early historical period, not only in Russia and Germany, but also in other countries. In particular, within the framework of a comparative study, long traditions of private schools in the UK were revealed, for example, the traditions of a private school in Canterbury (The King's School, Canterbury). The main objective of such closed private schools, widely used in various European countries, was not only a versatile development of a child, but also the strengthening of character, acquiring habits to control the personality, which were the considered the foundation of classical education. In this case, strict discipline, according to supporters of this model of education, was designed to develop independence and responsibility, to eliminate unwanted habits of students. Despite the fact that private schools were established as a prestigious environment that can provide opportunities for students of high intellectual and academic development, there were identified quite obvious negative aspects of this phenomenon, allowing to consider private schools as one of the variations of the total institution - the place of business and stay of people who are for a long time cut off from the outside world, are working together, have reclusive life, which forms are explicitly and carefully regulated. It was found that one of the principles of total institutions functioning is to reduce the "private sphere" of the individual characteristic of their "normal" existence. 
Such long-term separation from parents and native culture often led to the emergence of "third culture children" (a term introduced by sociologists David C. Pollock and Ruth E. Van Reken,), the children who spent a significant part of the period of active formation and socialization conducted outside the parental culture or culture of their country.

The study demonstrated that total institutions are characterized by the following: social limitedness of contact with the rest of society; unbridgeable distance between different social roles; formalised and tightly controlled daily life; moral and physical coercion as effective means to eradicate the expectations and habits associated with the former existence.

\subsubsection{Characteristics of the Reformist Stage}

This stage is characterized by the proliferation of the ideas of reform pedagogy at the end of the XIX and the early XX centuries in Russia and Western Europe. During the gradual spread in Russia of humanistic pedagogical ideas and the emergence of pedagogy of "free education", domestic educators started to create a community for children and youth with equal participation in their work for children and adults (e. g., "Home of a free child" by K. N. Wentzel).

The analysis revealed features of the interaction of children and adults in the "House of a free child", representing a type of children and adults communities: equal participation in the life of the House of children, their parents and teachers, both interacting and complementing each other's forces; fusion of family life with the school life in many of its manifestations; the absence of any coercion and violence against the child; rejection of the preliminary plans, programs, schedules (the only guide in education is the interest of the child); the dominant role of the free productive (manual) labour, which has close organic connection with the system of education, which the child would like to get; the changing nature of the teacher's activity, which primarily has "witness, expectant nature", and the teacher feels the "awe" in front of each child, being afraid to break his or her inner world (Wentzel, 1993).

In addition to the "Children's House", the example of a successful organization for children and adults communities, the study investigated the activity of the society "Settlement", created in the early XX century in Moscow on the initiative by A. U. Zelenko jointly with S. T. Shatskiy and L. K. Schleger. While solving important social, cultural and educational and health problem, the staff of "Settlement" adhered to the principle of freedom as the leading in their activities. Through various teaching methods applied to children attending the "Settlement", educators created a sense of equality with adults in all matters, but they quietly directed their choices and actions into a certain, suitable from the point of view of teachers, mainstream (Shatskiy, 1989).

The study of the pedagogical determinants of the reformist movement in Western Europe revealed the impact by the new pedagogical tradition in Russia, which emerged at the cusp of XIX-XX centuries; the main guidelines of those new traditions were the idea of "individual freedom" and "free education". Pedagogical centrism, approval of the child's right to manifest his or her identity, understanding of the essence of education as equal subjects of the free interaction of a community - all these make the process of reformist ideas development in Russia consonant with similar processes in Western Europe, which opened up possibilities of mutual enrichment of pedagogical cultures.

The study showed that teachers-reformers of Western European countries paid great attention to the cultivation of children and adults communities as "school communities" (P. Peterson), "just communities" (A. Neill), "self-governing free schools" (R. Schteiner) "integrated school-family homes" (Montessori \& Otto), "united children's groups" (S. Frene). The 20-ieth in Germany was marked by emerging schools-communities, the basics of which were: the principle of open school doors (working closely with the parents), the spiritual unity of teachers and collegial management, companionship teachers and students, which, according to G. Scharelmann, needs to "deepen to the level of the community". Providing a "living space" for social activities for children and adults, educators-reformers introduced self-government into school providing the equal right to everyone-from a 6-year-old child to the principal and parents. Democratic nature manifested itself in various forms of self-government, being introduced by educators-reformers in children and adults communities: P. Peterson speaks about "a self-governing free community" with the humanistic relations based on kindness and justice; S. Frene-"school cooperative headed by the council" with its own general meetings and print organ; V. Fiorster-"a school state", functioning on a democratic sample (Pevzner \& Raschiotina, 1995).

Followed by the historical stage of the development of scientific knowledge about the process of formation and development of children and adults communities, there was the stage of development of the theory of children's collective and pedagogics of community, which became widespread in the XX century. 
The main idea of this historical stage was the education of children in the community and through the community. In this case, the community was perceived by the founders of these theories (A. S. Makarenko, S. T. Shatskiy, V. A. Suhomlinskiy et al.), as a social group united by common goals, immediate joint activity, relations of "responsible dependence" (Makarenko, 2003; Shatskiy, 2011; Suhomlinskiy, 2001). In terms of formal and informal structures, L. I. Novikova and her employees researched the community. They paid special attention to the emotional and psychological system of connections and relationships in the community, revealed the socio-pedagogical characteristics of a group of children. V. V. Davydov, V. I. Slobodchikov, et. al. studied children and adults educational communities as a collective subject of educational activities. (Davydov, 2008; Slobodchikov \& Isaiev, 2000). V. I. Slobodchikov considers children and adults communities as an event community that is different from the symbiotic unity and formal organization (Slobodchikov \& Isaiev, 1995). The concept of a "community" in the domestic pedagogy is usually associated with the communist upbringing and had ideological character. That is why the 90 -ies of the XX century, the theory of a group of children was seen as an attribute of the past and has been unjustly forgotten, which largely contributed to the official direction for individualization, which was carried out in education during these years. As this stage is most fully represented in Russian literature, especially the Soviet period, and it did not require any additional study. The main attention was paid to the current stage of development of knowledge about the children's community that the study calls pluralistic.

\subsubsection{Characteristics of the Pluralistic Stage}

This stage is characterized by a variety of theories and concepts of children's community that contain ambiguous and contradictory interpretations of concepts such as "community", "group", "association", "organization", "collectivity" and others.

The same phenomenon of pedagogical reality in various theories may be referred to by various terms, and one and the same concept often has different meanings. The study demonstrated that many authors carry out the terminological analysis of the above concepts, highlighting the most characteristic features for them. Thus, Slobodchikov and Isaiev (2000) distinguish children and adults, symbiotic and events communities. Shustova (2003) developed a typology of children and adults communities in which there is socialization, development of the subjective qualities of children and adolescents identified the conditions under which children, and adults communities become a factor in their upbringing.

Alternative models of children and adults territorial communities are the topics of doctoral researches of a number of local authors. In their studies, they suggested productive ways of forming such communities: creative methods (E. L. Vshivkova); dialogue and leadership, substantive, interdisciplinary research and above substantive projects (O. A. Donskaya); cultural and educational activities (T. K. Govorushina); intergenerational resource and genes- and sociogram (E. A. Petrova).

A comparative study showed that the idea of subject-subjective interaction and the development of children and adults community today is the concern of not only Russian, but also foreign teachers. These ideas in varying degrees become an objective reality in the majority of foreign educational institutions. This is largely due to the changing role of the teacher. In the XXI century, the alternative role to the authoritarian conductor of knowledge held by teachers for quite a long time, transforms into the alternative position of organizer, facilitator-inspirer, mediator, creating conditions for the formation of interpersonal relationships (learning through interactions). Partnerships and subjectivity of the child become the basis for interage interaction in US preschools. According to the concept of High Scope, emerged in the US in the 90s of the XX century, pre-school education of a child shall be based on the principles of equality and support. Representatives of the educational doctrines offer the following strategies interaction of children and adults: participation in joint games; conversations on equal terms; approval, support (instead of praise); creating conditions for solving the problems by children.

US researchers pay much attention to the development of the local model of children and adults territorial community (local community). The generally accepted in the United States and Western European countries term community means, as a rule, a group of people living in the same area and having similar cultural and historical heritage. From the point of view of researchers, important are such parameters as the similarity of interests, unity of management, customs and traditions, language, religious community and others.

Activities of the community involve the creation of conditions for the inclusion of its certain representatives into the solution of social problems: fight against racism, prevention of criminal behaviour, etc. It is the variety of different characteristics possessed by the representatives of a community allows, according to the researchers, to find effective solutions to pressing problems of the local community (Wool, 1993).

To date, various representatives of the community are united by the so-called "community centres", which 
represent a platform for interaction and communication between representatives of the local community to provide social support and public awareness. Most often they are represented by schools that provide the population with its building, equipment, etc. (Zritneva \& Klushina, 2006). Community centres perform the following functions: platform for celebrations and general meetings; place for clubs functioning, hobby groups and voluntary associations; rent for large scale private events (weddings, celebrations, etc.); preservation and transmission history of the local community.

The modern pedagogy still has the relevant concept of a multigenerational society. The idea of multi-generation is to ensure equal rights and opportunities for everyone, whether young people or older people, people with disabilities, representatives of different faiths and nationalities.

Today the concept of community education/community-based education/community learning and development gains more and more popularity, which refers to educational groups or individual members of local communities using both formal and informal methods. This phenomenon is a kind of example for social partnership, as the education is implemented in direct dialogue with the representatives of the local community. The purpose of education is to improve the quality of life, increase the capacity of local community and its individual representatives. Education in the community is opposed to formal education in schools and colleges in the sense that it allows reaching social groups, deprived of access to education.

In describing the children and adults communities, a number of studies often use the term of "intergenerational practice". In the most general sense, this phenomenon can be described as the interaction of the elderly (over 50 years) and the younger (under 25 years) generations in some joint activities. Representatives of the Centre of intergenerational practices in the UK describe them as "an association of people in focused, mutually beneficial and meaningful activities that promote mutual respect and understanding between generations and is aimed at strengthening the community. Intergenerational practices are based on positive personal baggage that young and elder people can share with each other" (Kaplan, 2001, p. 3). In the study by UNESCO, intergenerational programs are represented as a means to keep focused exchange of resources and education between the younger and older generations.

In theoretical and methodological terms, intergenerational practices are a field for discussions on various parameters. Organizers disagree on whether to involve adults into intergenerational projects (intermediate generation), as well as if it is acceptable for relatives to participate in such programs (grandparents and grandchildren). Most often intergenerational projects have the prevention of ageism as one of the purpose, therefore it is desirable to eliminate communication of the relatives. In addition, the study found, that theorists and practitioners have different understandings of the phenomenon of intergenerational practices. Some of them distinguish the organization of intergenerational interaction in the independent sphere of professional activity that requires a separate training and qualifications, while others consider intergenerational practice as an approach to solve various social problems, which can be used by specialists in various fields (Höpflinger, 2010).

In the study, it was found that the nature of the interaction and content of many intergenerational programs can be divided into several large groups: representatives from one generation help each other; representatives of both generations are working together on one of the socially significant problems; representatives of different generations, participating in joint education.

The analysis of intergenerational projects and programs in local communities by Pain R. et al. refers to the most common types of joint activities of representatives of different generations. Among them are creativity (theatre, singing), arts and crafts, and other creative activity, the transfer of knowledge and skills, mentoring, historical studies, videos and photos, discussion and solution of social problems, and the community mapping. The main objectives of intergenerational projects include the following: strengthening social inclusion of different social groups in the life of the community, support of mutual understanding of different cultures, solidarity and neighbourly relations, protection and restoration of the environment, improving health and well-being, education, reduction of criminogenic environment and safety in the community (Pain, 2005).

The organization of intergenerational practice is based on creating an environment in which each side sees significant positive results of the interaction. In the course of communication and activity and jointly with the young people, the older generation rediscover their own value to the society. In the process of increasing their motivation for activity, social isolation is reduced. Elderly people have the opportunity to share existing skills and to learn something new. The general condition of an elderly person is improved, including health and well-being level (Guide, 2011). For youth, the intergenerational practice is an enabling environment for the formation of social responsibility and cultural continuity, increase of self-esteem (through participation in socially significant activities), formation of valuable relationships with adults. According to Zeldin S. and Larson 
R., the intergenerational relations perform a kind of protective and preventive functions, allowing the prevention of manifestations of deviant behaviour in adolescents and, in contrast, contribute to the development and improvement of social competence of the younger generation (Zeldin et al., 2005).

As a result, the organization of intergenerational practices brings benefit not only the participants, but also to the society as a whole. A unified field of values is formed in the community, alienation is weakened, conflict potential of the medium is reduced, and a strategy of mutual aid and support in the community is formed. Strengthening intergenerational relations plays a key role in ensuring sustainable development of local communities (sustainable communities).

The practices of intergenerational interaction today are well represented in various European countries where the problems of population aging and the creation of conditions for comfortable and full of life in old age became the concern to the public in the second half of the XX century. The European Union, UNESCO, and other international organizations actively support development of intergenerational learning, intergenerational mentoring and other projects promoting harmonization among different ages.

The examples of the intergenerational interaction practices are the intergenerational club within the framework of the project "Big Together" in the Camden borough (London, England), intergenerational learning project on skills development and the creation of digital photography prints named "Digital Photography and Book Project" in Derbyshire, activities of the environmental school club named Swynnerton Youth Club (Staffordshire, England), and the Centre of intergenerational practices (Beth Johnson Foundation, 2009). The main purpose of the latter is advisory and methodological support of intergenerational interaction, as well as the use of educational and socio-cultural potential of intergenerational relations in solving social problems. To date, intergenerational projects under the Centre control are implemented throughout the UK.

To understand the essence of intergenerational relations in children and adults communities, German authors introduce the term of "generativity" (Generativität), which represents an interest in the next generation and education, namely the transfer of knowledge, values, norms, and culture. This concept refers to the need of an individual in the implementation of socially important functions, which manifests itself in care, education, promoting socialization of children and grandchildren. Generativity is not limited to family relationships, it goes far beyond them, has social character, and is reflected in the preservation and augmentation of wealth and responsibility for the younger and future generations (Keil, 2012, p. 8).

The example of inter-generational project is social work carried out by the charitable organization named Caritas run by the Catholic Church in Vienna (Austria). This organization provides an opportunity for meeting and dating, supports social activity, and attempts to introduce and organize communication between people of different social and cultural background, age, and gender. Its ideal is the equal chances for everyone, joint activity and willingness to share with others. The basic principles of the organization are the following: empathy, respect, inclusion, active participation, solidarity, increasing competence, sensitivity to cultural and gender differences, reference to the resources (to already available, to strengths), orientation in social space. In particular, we speak, for example, about the project "Dance tolerance" (Tanz die Toleranz) by Caritas, where the participants are people of different age, gender, and nationality. Another project implemented by Caritas is the housing management in the new district of Vienna (from Feb 2013 to Sep 2014). The objectives of this project included establishment of intergenerational contact between neighbours, creating opportunities for them to meet and communicate; support private initiatives of the residents and their self-organization; resolution of conflicts between neighbours (Gretner, 2008).

The example of children and adults community aimed at co-education of generations, is the research and development project named "Generations study together: sustainable development" (Generationen lernen gemeinsam: Nachhaltigkeit), which was led by A. Scheunpflug and J. Franz from the University of Erlangen and Nuremberg. The project helped to develop and conduct training seminars on "intergenerational learning", to prepare multipliers, who developed intergenerational projects on sustainable development, and the projects were implemented later in practice in various institutions of adult education in Germany (Franz \& Frieters, 2009).

The conducted study of the main historical stages in the development of knowledge about the formation of children and adults educational communities allowed determining the theoretical assumptions of the development conceptual model for these communities.

The following can be considered as the latter:

- The concept of reform pedagogy and free education (N. Wentzel, M. Montessori, A. Neill, B. Otto, P. Peterson, L. N. Tolstoy, S. Frene, R. Steiner et al.), within the framework of which the following was developed: an 
alternative approach to the child's personality, recognizing the uniqueness and originality of its nature, an alternative approach to the organization of the new school, which required deep upheaval in the organization of the school life, the transformation of the school of "study" into the school of "life", including in the learning process manually-sensory way of knowing; an alternative approach to the creation of living space for children, combining an appeal to the child, the recognition of their unique personality with social motives, civic education, cultivating of communities (Wentzel, 1993; Montessori, 1993; Neill, 2000; Pevzner \& Raschiotina, 1995);

- Provisions of humanistic psychology (A. G. Asmolov, V. P. Zinchenko, A. N. Leontiev, A. Maslow, K. Rogers et al.), which are based on the understanding of the humanization of the person and the humanization of education as a constructive change of people involved in the educational process and the construction of humanistic relations at an educational institution (Asmolov, 1990; Zinchenko, 1994; Leontiev, 2001; Maslow, 2002);

- The theory of a group of children (A. S. Makarenko, V. V. Rubtsov, V. A. Suhomlinskiy, G. A. Zukermann, S. T. Shatskiy et al.), which is based on the idea that the development of the child's personality is mediated by children's groups, representing a complex socio-educational system, an important feature of which is the social orientation and psychological community. The theory of the community, based on the idea of "education in the community and through the community" identified both positive and negative effects on the child's personality. With proper pedagogical instrumentation, the community can develop the individuality and creativity of the child's personality, and in its absence generate the process of personality levelling. Theoreticians for a group of children developed provisions on stages for the community development. Its formal and informal structure, the systems for relations of children and adults in a group (Makarenko, 2003; Suhomlinskiy, 2001; Shatskiy, 2011);

- And theory of social communities (Yu. V. Gromyko, V. V. Davydov, V. I. Slobodchikov, I. Yu. Shustova et al.), which is considered a children and adults community as a collective subject of learning activities, as well as the object and the subject of education. Theorists of this area were solving the following tasks: systematization of theoretical and methodological approaches to understanding children's community as a socio-pedagogical phenomenon, the development of children's prosocial typology of communities, identifying the place and role of an adult in the formation and development of the children's community, determining the conditions of actualization of the educational potential of children's community (Davydov, 2008; Slobodchikov \& Isaiev, 2000; Shustova, 2014).

3.2 The Study of the Main Characteristics of Children and Adults Educational Communities (on the Example of the Novgorod Region)

To determine the leading characteristics of children and adults educational communities in Veliky Novgorod and the Novgorod region, the polling method was used to carry out an empirical research of the interviews of 192 representatives (32 teachers and 160 parents) for children and adults communities of 5 types of educational institutions (school, gymnasium, college, university, education centres). The study revealed the following.

The most significant characteristics of children and adults communities according to the respondents are the following: commonwealth of adults and children to solve social and practical problems of society (76\%); interaction of adults and children in an atmosphere of dialogue, which manifests a sense of solidarity and community (82\%); uneven composition of groups, allowing the participants to live the positions of a junior and a senior, a knowledgeable and an ignorant ones, expecting help and assistance (67\%); inclusion of children and adults not only in interpersonal relationships, but also in the system of social relations defined by the state and society $(72 \%)$; mastery of the community in ways means of interaction with the surrounding society (56\%); community of adults and children, providing continuity, transmission of cultural, educational and other national traditions and customs (64\%). It is noteworthy that parents of school-age children and parents with many children believe the main characteristic to be the presence of mixed-age groups of the community of adults who view children as like-minded persons.

The major strengths of children and adults communities according to survey participants are the following: the formation of human values; the feeling of solidarity, community; the freedom for a child in choosing an interlocutor; creation of a new field of communication through the joint gaming and other educational activities; strengthening intergenerational ties.

The study identified the conditions of forming the successful children and adults community: availability of meaningful educational activities, interesting leisure; implementation of programs to meet individual interests, abilities and level of development of particular children and adults groups, including special programs for persons with disabilities; availability of educational and leisure practices; creation creative friendly atmosphere. 
The most effective forms of children and adults communities according to the respondents are the following: museums-clubs of local historical, military-patriotic and other orientation (56\%); children and adults search groups (34\%); tourist and local historical expeditions (32\%); centres of social engineering (11\%); children's self-management and co-management of children and adults (87\%); children's public associations and organizations of different directions (43\%); escort service, including representatives of different generations (38\%); family theatres; clubs of different orientation (74\%).

Productivity indices for formation of a children and adults territorial community, according to respondents, are the following: the emergence of "convergence effect" between an adult and a child (92\%); a high degree of satisfaction of both children and adults with joint communication, activities and relationships in the group (78\%); comfortable morale in the group (83\%); harmony of intergenerational relations $(67 \%)$; "acceptance" of all members of the community, the ability to self-realization (79\%).

The study includes interviews of parents of school-age children, for their participation in children and adults communities belonging to different models. The survey found that the most common models of children and adults educational communities are local (schools, educational centres (intelligent courses), school museums, art studios, tourist and local history of the expedition, and others) and contact (family, school classes, kindergarten groups, mugs arts and crafts, children's vocal ensemble, musical theatres, school media centres and other) models. Along with local and contact models in the Novgorod region territory, the network models for children and adults communities are registered as well, which include, first of all, such volunteer movements as the "Red Cross", the "Ecological path", the Fund "There is no somebody else's children", etc. If the contact and local models of formal and informal nature involve virtually all children residing in the Novgorod region, the network model does not cover such a large number of participants (approximately 6-7\% of the total respondents).

The study demonstrated that in various models of children and adults communities, there are the following types of intergenerational relations: care for the people of the older generation; the provision of educational services to people of all ages; mutual learning; co-creation, and others.

As it is known, one of the types of network communities is children and adults virtual community. The American scholar of social relations in the network, G. Rheingold (Rheingold, 2004), first used the term of "virtual community" in the research papers. The study took into account that the virtual community is a new form of network model for children and adults territorial community offering innovative ways to engage children and adults, due to their specific characteristics, to the peculiarities of the Internet as a communications medium (Ivanov \& Asmolovskaya, 2011). The research demonstrated that the formation and stable existence of the virtual community as a social group is only possible if the participants of the network resource share common interests, jointly developed goals and organized actions to achieve them, which are implemented within a single communication space. The main socio-psychological mechanisms of virtual communities' formation are the mechanisms of motivation, social perception, social identity, the mechanisms of action, and role models of infection and mocking (Bondarenko, 2004).

According to the study carried in Veliky Novgorod, which was attended by 97 students, including: a) the age group of 10-12 years (22 people); b) 13-15 years (26 people); c) 16-18 years (49 people), it was found that the most popular among the Novgorod schoolchildren are the following social networks (descending): "VKontakte"-100\%; "Google+"-38.5\%; "Facebook"-35\%; "My World (mail.ru)"-31\%; "Instagram"- $21 \%$.

The motives that prompted the schoolchildren to join social networks (multiple choice) were the following: a) personal initiative - 79\%; b) a desire to be modern-35\%; c) the advice of friends-26\%; d) advertising - $4 \%$; e) the ability for convenient communication $-4 \%$; g) recommendations of relatives $-3 \%$; e) a desire to satisfy own interest- $3 \%$; i) teacher's advice- $1 \%$.

The respondents see the following benefits in their presence in social networks: a) the opportunity to take free time, a way to organize leisure, entertainment- $79 \%$; b) expanding the range of communication- $78 \%$; c) maintaining contact with relatives and friends-72\%; g) search for useful links, information-64\%; e) expanding the range of contacts, acquaintances $-41 \%$; e) the opportunity to express own views $-25 \%$.

The study revealed the growth dynamics of schoolchildren involvement into virtual communities in which adults are present. A large percentage of schoolchildren are willing to participate in these communities.

The reasons for choosing virtual communities with the presence of adults, the schoolchildren noted the following: "Adults are more aware and can give advice", "one can learn something new", "very interesting to talk to", "nice to have common interests with adults", and "adults have more life experience". At the same time, respondents 
noted a number of reasons why they do not want to communicate actively with adults. The main reasons are the lack of common interests and common themes, arrogance of adults towards children, instructive tone in communication, unwillingness to accept a child as an equal one, adequacy of communication with peers.

The topic for the joint communication with adults, schoolchildren choose books, music, movies, humour, news of school life, cars, news and politics; appearance, clothes and make-up; sports, games, proper nutrition; healthy lifestyle; photos, helping animals, helping people, useful tips, the relationship between people and travelling.

Thus, the virtual community as a kind of network model of children and adults territorial community is a social group of children and adults, united by similar interests, goals, and practices, which prolonged interaction is completely or at least partially carried out by means of the Internet and is regulated by specific communication procedures and standards. Virtual community is a new form of social group that differs, firstly, by the interactive nature of interaction between participants of communication, regardless of age-sensitive specification; the participants may mutually exchange information, which in setting the specific pedagogical purposes can have an educational effect; secondly, the lack of territorial and psychological barriers to communication, which is due to the anonymity of communication on the Internet, limiting the possibility of hierarchical dependence of children from adults; thirdly, by the possibility of self-expression, and taking into account the existing individual abilities, which in real life activity may have a hidden character; fourthly, voluntary membership and an informal structure of communication in real time; fifthly, the possibility of relatively quick overcome of psychological complexes and communication barriers and forming their own social circle.

The study demonstrated that virtual communities are an effective tool for interactive communication for children and adults. The majority of respondents are open to the online interaction not only with their peers, but also with the older generation. In this regard, one of the objectives of children and adults virtual communities is to develop the readiness for intergenerational interaction by both the children and adults.

Thus, based on the historical, reflexive, and comparative benchmarking of intergenerational relations in children and adults communities in Russia and abroad, as well as on the experimental studies of these phenomena in the Novgorod region, the basic model of children and adults territorial communities were determined and theoretically proved.

\section{Discussion}

The diversity of models of children and adults territorial communities is associated primarily with different interpretations of the term "territory", which can be understood in a narrow and a broad sense of the word. Depending on what area the children and adults community is formed and developing, we can talk about its various models.

In a broad sense, the term "territory" can be represented both at the macro and meso levels. At the macro level, the territory is an administrative unit that has defined geographical boundaries and relatively constant composition of the population. A network model characterizes this type of area for children and adults communities. The network model for children and adults educational territorial community means a set of primary groups of children and adults within the territory, having strong ties and relationships, both within their communities and with each other on the network in the presence of coordination, custody, mediation or other forms of influence from the part of the administration of the territory, territorial public organizations or other individuals and groups, reflecting the interests of the territory and its value orientations in the field of intergenerational relations and communications, as well as education and the education of future generations. The study demonstrated that the most widely applied are such types of network model for children and adults community as children's public associations of different directions, children and adults association of search units, tourist and natural history expeditions, etc. Especially popular among children and adults is the kind of network model having super territorial level as virtual children and adults community. The study allowed for the conclusion that the network model for children and adults community consists of two sub models: the real and the virtual.

At the meso level (for our study it was the most important), the territory is the part of the administrative unit, having close relationship between its subjects - educational institutions, sports, businesses, and organizations uniting various groups. In this sense, we are talking about the neighbourhood as part of an urban settlement, which is usually set up bodies to coordinate the activities of the subjects within the territory.

The study found that the local model characterizes this type of area for children and adults educational community. The local model represents both the primary community of children and adults (intra-organizational sub-model) and merging of several primary groups or entities, with constantly changing membership, united by 
the common goal of sharing experience and events, while maintaining the balance of stability and variability of connections and relationships (inter-organizational sub-model).

The territory in the narrow sense is a certain space used to build the system of stable and close relationships between people and objects that fill this space. Based on this, at the micro level, the territory is limited to the spatial area within a continuum to implement within the direct communication, direct contact between individuals united by joint activities within the formal organization or informal association. The micro-level model is characterized by the contact of the children and adults educational territorial community, which represents the primary group of children and adults with stable relations, similarity of interests and lifestyles, joint activities and functioning in a limited spatial scope of the territory. This model includes the generic sub-model (family) and the converged - unrelated sub-model (classroom, sports clubs, art studios, etc.). The study revealed that the contact model is the most common model of children and adults territorial community, which may be used for more focal investigation of intergenerational communication, identification of problems and conflicts that arise between members of different generations, trends, and strategies for the development of intergenerational relations.

Empirical studies conducted in Veliky Novgorod and the Novgorod region have allowed the definition of the essential characteristics of children and adults educational community, which include the following: immersiveness - a sense of being immerse to each other, a sense of belonging to a common circle, similarity of interests and lifestyles, complementarity (the term by L. N. Gumilev), i.e., mutual attraction, mutual sympathy, the desire to be together, complementarity - the complementarity of community members, informal relations, social localization of education, the presence of stable and changing intergenerational ties and relations, event- $\mathrm{a}$ joint existence, experience sharing events, spiritual community, being with others, balance of stability and variability of connections and relationships, involvement in joint activities for children and adults.

\section{Conclusion}

The study enabled the authors to analyse the development of scientific thought on the pedagogical potential of children and adults community, as well as the dynamics of studies in Russia and abroad on this issue. The particular emphasis was placed on the characterization of intergenerational relationships in these communities. For the first time, the notion of "children and adults territorial community" was given, the typology of children and adults territorial communities was designed, which may be the subject of discussion by representatives of educational theory and practice around the world. The empirical study conducted in the Novgorod region enabled the authors to identify the most important characteristics of children and adults communities in the assessment of teachers and parents and in some parameters to compare these estimates and identify their differences. The study revealed the most common forms of children and adults communities, which became widespread in the region, defined the conditions and indicators of success and efficiency of children and adults territorial communities. The models for children and adults communities developed in the theory were studied in a particular practice and features of their organization and functioning were identified. Particular emphasis is placed on children and adults virtual communities representing a new form of network interaction between various individuals and groups.

In the future, the authors plan to correlate the results of the study, obtained in the Novgorod region, with similar data in Russia and abroad, and to determine the features and perspectives of intergenerational relations in different kinds of communities. The authors suggest to develop strategies for the development of intergenerational relations in children and adults territorial communities, identify trends and potential opportunities for children and adults territorial communities in developing sustainable relationships between people of different generations.

\section{Acknowledgment}

The authors express their gratitude to the Ministry of Education and Science for the grant \#27.1559.2014/K, in which framework the research for children and adults communities was conducted. The grant allowed for the historical and pedagogical analysis of the development of children and adults communities in Russia and abroad, as well as exploration of the current models of these communities on the Novgorod region example.

We express our sincere gratitude to the teachers and students of the Novgorod State University, which supported the study and contributed to the realization of its goals and objectives: we are grateful to the Professor E. V. Ivanov and the student D. E. Ivanova for the analysis of historical sources and archival material, which allow for retracing the development of children and adults communities in the historical perspective; to the associate professor E. V. Yegorova and senior lecturer A. G. Kukushkina for their comparative analysis of the English-speaking and German-speaking sources, reflecting the development of children and adults communities. 
We express our gratitude to all the members of the research team, taking part in the project. The most gratitude is expressed to the Director of the R\&DE of NovSU, D. V. Kovalenko, for administrative and financial support of our research.

\section{References}

Asmolov, A. G. (1990). Psychology of personality (p. 367). M.: Publishing house of MSU.

Bondarenko, S. V. (2004). Social structure of virtual network communities: Dissertation by the Doctor of Sociological Sciences.

Davydov, V. V. (2008). Problems of developing education (p. 613). M.: Direct-Media.

Franz, J., \& Frieters, N. (2009). Scheunpflug, Annette; Tolksdorf, Markus; Antz, Eva-Maria: Generationen lernen gemeinsam. In Theorie und Praxis intergenerationeller Bildung. Bielefeld.

Gretner, S. (2008). Project "Tanz die Toleranz". Retrieved from $\mathrm{http} / /$ www.fgoe.org/veranstaltungen/fgoe-konferenzen-und-tagungen/generationen-und-generationenbezieh ungen-im-wandel-herausforderungen-fur-die-gesundheitsforderung/WS\%202_DI\%20Sabine\%20Gretner.pd $\mathrm{f}$

Guide, A. (2011). Intergenerational Practice, Center for intergenerational practice. Retrieved from http://www.centreforip.org.uk/res/documents/publication/BJFGuidetoIPV2\%20\%2028\%20Mar\%202011.pd $\mathrm{f}$

Höpflinger, F. (2010). Generationenbeziehungen im Wandel. Retrieved from http://www.thun.ch/fileadmin/behoerden/soziales/media/pdf/Generationenbeziehungen_im_Wandel_Hoepfl inger_23_10_2010.pdf

Intergenerational Practice, Policy and Performance: A Framework for Local Authorities Beth Johnson Foundation. (2009). Retrieved from http://www.oneeastmidlands.org.uk/node/1585

Ivanova, E. O., \& Asmolovskaya, I. M. (2011). The theory of education in the information society (p. 190). M.: Proscveshcheniie.

Kaplan, M. S. (2001). School-Based Intergenerational Programs (p. 46). UNESCO Institute for Education.

Keil, S. (2012). Generationenbeziehungen-Herausforderungen und Potenziale. Gutachten des Wissenschaftlichen Beirats für Familienfragen beim Bundesministerium für Familie, Senioren, Frauen und Jugend. Bundesministerium für Familie, Senioren, Frauen und Jugend (Hrsg.) Berlin. Retrieved from http://www.bmfsfj.de/RedaktionBMFSFJ/Broschuerenstelle/Pdf-Anlagen/Generationenbeziehungen-Heraus forderungen-und-Potenziale-Gutachen,property $=$ pdf,bereich $=$ bmfsfj,sprache $=\mathrm{de}, \mathrm{rwb}=$ true.pdf

Leontiev, A. N. (2001). Lectures on general psychology. M.

Makarenko, A. S. (2003). The pedagogical poem (p. 720). M.: ITRK.

Maslow, A. (2002). Motivation and personality (p. 480). SPb.

Montessori, M. (1993). Method of scientific pedagogy applied to child care in children's homes (p. 168). M.: Typ. Gossnaba.

Neill, A. (2000). Summerhill: Education by freedom (p. 296). Moscow, Pedagogika-Press.

Nikitin, V. A. (1998). Organizational types of modern culture: Thesis abstract of the Doctor of Cultural Studies (p. 49). Togliatti, M.

Pain, R. (2005). Intergenerational relations and practice in the development of sustainable communities. Durham University. Retrieved from http://www.centreforip.org.uk/res/documents/publication/ ODPM\%20intergenerational\%20report.pdf

Pevzner, M. N., \& Raschetina, S. A. (Eds.). (1995). Alternative models of education in comparative education: Training and methodological complex for students of pedagogical universities (Ch. 2). Novgorod: NovSU.

Rheingold, H. (2004). The virtual community.

Shatskiy, S. T. (1989). The work for future: Documentary narrative: The book for teacher (V. I. Malinin \& F. A. Fradkin, Comp.) (pp. 77-78). M.: Proscveshcheniie.

Shatskiy, S. T. (2011). Let us keep what is in the children (p. 352). M.: Karapuz.

Shustova, I. Y. (2003). Children and adults community as a condition of formation of value-sense orientation of a 
child. Bulletin of PSTGU.IV: Pedagogics. Psychology, 1(28), 51-61.

Shustova, I. Y. (2009). Factor of children and adults community in the education and development of the youth subjectivity (thesis abstract of the Doctor) (p. 4). Moscow.

Shustova, I. Y. et al. (2014). Children's community as a socio-pedagogical phenomenon. Innovations in vocational school, 8,48 .

Silvester (Ed.). (1994). The Domostroy. M.: Nauka.

Slobodchikov, V. I., \& Isaiev, E. I. (2000). The main stages of development of human subjectivity. In Psychology of human development: The development of subjective reality in ontogenesis: Textbook for universities (pp. 212-385). M.: Shkolnaya Pressa.

Slobodchikov, V. I., \& Isaiev, E. I. (1995). Psychology of a human being: Textbook for universities (p. 384). M.: Shkola-Press.

Suhomlinskiy, V. A. (2001). On parenting (p. 436). M: KVANTA+.

Vul, B. (1993). Social assistance program in the American community. In T. F. Yarkina, \& V. G. Bocharova (Eds.), Theory and practice of social work: Domestic and foreign experience (Vol. 1). M.-Tula.

Wentzel, K. N. (1993). Free education: Collection of selected papers (L. D. Filonenko, Comb.) (p. 169). M.: Academy of Postgraduate Education.

Zeldin, S., Larson, R., Camino, L., \& O'Connor, C. (2005). Intergenerational relationships and partnerships in community programs: Purpose, practice, and directions for research. Journal of Community Psychology, 33(1), 1-10. http://dx.doi.org/10.1002/jcop.20042

Zinchenko, V. P., \& Morgunov, E. B. (1994). Worlds, structure and dynamics of the consciousness. A man developing - Essays on Russian psychology (pp. 162-210). M.: Trivola.

Zritneva, E. I., \& Klushina, N. P. (2006). Family studies: Textbook for university students enrolled in the direction of training and specialty of "Social work" (p. 246). M.: VLADOS.

\section{Copyrights}

Copyright for this article is retained by the author(s), with first publication rights granted to the journal.

This is an open-access article distributed under the terms and conditions of the Creative Commons Attribution license (http://creativecommons.org/licenses/by/3.0/). 